\title{
Application of Water Indices in Surface Water Change Detection Using Landsat Imagery in Nepal
}

\author{
Tri Dev Acharya, ${ }^{1}$ Anoj Subedi, ${ }^{2}$ He Huang, ${ }^{3}$ and Dong Ha Lee ${ }^{1 *}$ \\ ${ }^{1}$ Department of Civil Engineering, Kangwon National University, \\ 1 Kangwondaehak-gil, Chuncheon, Gangwon 24341, Republic of Korea \\ ${ }^{2}$ Institute of Forestry Pokhara Campus, Tribhuvan University, Pokhara 33700, Nepal \\ ${ }^{3}$ School of Geomatics and Urban Spatial Information, Beijing University of Civil Engineering and Architecture, \\ Beijing 100044, China
}

(Received April 16, 2018; accepted March 13, 2019)

Keywords: Landsat, water index, NDVI, NDWI, MNDWI, WRI, SWI, change detection, Sheyphoksundo, Phewa, Koshi

Surface water change is a very important indicator for environmental, climatic, and anthropogenic activities. Remotes sensors, such as Landsat, have been providing data since the last four decades, which are useful for extracting land cover types such as forest and water. Researchers have proposed many surface water extraction techniques, among which index-based methods are popular owing to their simplicity and cost effectiveness. By using the standard and Otsu threshold methods, water features can be mapped, thus changes can be detected. On the basis of the results of this study, the following water indices were applied, i.e., normalized difference vegetation index (NDVI), normalized difference water index (NDWI), modified normalized difference water index (MNDWI), water ratio index (WRI), and simple water index (SWI) for surface water extraction, and their changes using Landsat images. Three unique test sites from Nepal, which represent overall types of water features found in the country, were selected for this study. A model was developed in ArcGIS to differentiate the water features based on index methods and changes were calculated in terms of positive and negative. The results show that most of the case water index methods based on standard and Otsu thresholds cannot accurately separate water from its nearby backgrounds, such as melting ice, shadows of hills with or without vegetation, grasslands, and wet barren sand. From the current cases, it is not recommended to use the water indices in Nepal without any appropriate expert opinion or sitewise calibrated thresholding for automated water detection. However, they can be used for the overall change detection. Most of the change maps of the selected lakes showed good accuracies in some unique cases, such as the dark shadow and forest near a water body. SWI is good for stagnant lakes but not for water bodies with shifting features, such as the Koshi River. The model can be very useful in quickly understanding the changes in water bodies and taking the necessary measures to planners, but not much in accurate mapping. Furthermore, studies of different seasons, sensor data, and sites are necessary in the use of standard water indices for accurate change detection.

*Corresponding author: e-mail: geodesy@kangwon.ac.kr https://doi.org/10.18494/SAM.2019.2264 


\section{Introduction}

In recent years, Earth's surface has undergone various land cover/land use changes. Detecting these changes or specific classes such as farmland, forest, urban, and water has been proven to be important in various studies. However, these changes are slow and take a long time and thus, they are unnoticed unless they occur at large extents. To detect, understand, and prevent these changes, long historic data provides concrete evidence to the scientific community.

Surface water is a very vital resource in everyday life. Some of its uses are for drinking, irrigation, aquaculture, and thermoelectric cooling. Surface water is also a very good indicator of land cover changes in environments affected by environmental, climatic, and anthropogenic activities. Remote sensing combined with a geographic information system (GIS) can prove useful in monitoring current conditions and spatial and temporal changes of rivers, lakes, water reservoirs, and other surface waters. Remote sensing has not only become a backbone of hydrogeological reconnaissance in areas with insufficient field data and detailed map coverage, but also has become a relatively low cost alternative for feature detection and understanding hydrogeological systems in well-mapped regions. ${ }^{(1)}$

Nepal is a geographically diverse country with flats in the south and increasing hills towards the north to the mighty Himalayas. In Nepal, around $70-90 \%$ of the total annual rainfall occurs during the monsoon period, resulting in high runoff and sediment discharge and causing surface water area changes. ${ }^{(2)}$ Thus, it is rich in water resources with about 600 rivers $^{(3)}$ and 5358 lakes. ${ }^{(4)}$ About 225 billion cubic meters (bmc) per annum or equivalent to an average flow of $7125 \mathrm{~m}^{3} / \mathrm{s}$ is estimated to be surface water in Nepal, out of which only $15 \mathrm{bmc}$ per annum is used. Around $95.9 \%$ of the $15 \mathrm{bmc}$ is used for agriculture, $3.8 \%$ for domestic purposes, and only about $0.3 \%$ for industry. On the basis of the Water and Energy Commission Secretariat (WECS) report, $78 \%$ of the average flow of the country is available in the first category river basins, $9 \%$ in the second category river basins, and $13 \%$ in the numerous small southern rivers of the Terai. Out of which, the first category rivers have surplus flow, but the second category rivers have deficit flow in the dry season. ${ }^{(3)}$ On the basis of the altitude, 2712 lakes $(51.0 \%)$ were found to be distributed below $500 \mathrm{~m}, 2227(42 \%)$ above $3000 \mathrm{~m}$ and only $419(<8 \%)$ were in the mid hills of the altitudinal range between 500 and $2999 \mathrm{~m}^{(4)}$ These rivers and lakes have global significance as well as potential for trans-Himalayan conservation. Besides being rich in biodiversity, they support many ethnic groups and livelihoods, and are the foundation of religious and cultural developments. However, they are under threat by anthropogenic and natural processes. ${ }^{(5)}$ Few previous studies of mapping surface waters have been conducted; ${ }^{(6-9)}$ however, regular mapping, monitoring, and change detection from field works and even regular validation to high Himalayas are lacking in Nepal.

A series of optical remote sensors such as Kompsat, Landsat, Spot, and Worldview have been used to continuously observe and capture images of the Earth's surface over the last four decades. They provide low-cost and reliable information on environmental changes at local, regional, and global scales, with their long collected repeatable and even real-time data. ${ }^{(10,11)}$ Owing to the availability of free continuous optical remote-sensing images of high temporal 
resolution to the scientific community, Landsat series are the most common optical remote sensors for mapping water features. ${ }^{(10,12-20)}$ Landsats 5,7 , and 8 have always been used to enhance the acquisition of data from a predecessor yet maintain the legacy of continuous data application. ${ }^{(21)}$ Over the past years, numerous water extraction algorithms have been developed and applied to optical remote-sensing images. ${ }^{(10,12-14,17,22-26)}$ Broadly classified into four categories are (a) digitizing through visual interpretation, which is highly accurate but labor-intensive, (b) density slicing of a single band, ${ }^{(20,27,28)}$ which applies a fixed threshold in a given spectral band, (c) calculating spectral indices, ${ }^{(24,29-33)}$ which combines two or more bands by mathematic ratios, and (d) classifying multispectral data using unsupervised ${ }^{(34)}$ and supervised techniques. ${ }^{(35-38)}$

Owing to their simplicity, low computational cost, and superior performance based on specific noises, water index methods are widely used for the identification of water features. ${ }^{(11,39)}$ These methods have achieved extremely good results with Landsat images. ${ }^{(13,37,40)}$ Some of the most well-known multiband water index methods include the normalized difference water index $(\mathrm{NDWI}){ }^{(33)}$ modified NDWI $(\mathrm{MNDWI}){ }^{(31)}$ and automated water extraction index (AWEI) ${ }^{(24)}$ methods. The NDWI method was developed to identify water surfaces from Landsat images using green and near-infrared (NIR) bands to maximize water feature identification. McFeeters proposed the use of zero threshold to separate water with background, ${ }^{(33)}$ but $\mathrm{Xu}^{(31)}$ noted that the use of zero threshold was not appropriate and has errors over built-up lands. Using the midinfrared (MIR), MNDWI from Landsat Enhanced Thematic Mapper Plus (ETM+), the MNDWI method overcomes NDWI problems by removing built-up lands and soil noises. Similarly, the AWEI method was proposed by Feyisa et al. ${ }^{(24)}$ to identify water features in two different conditions: $\mathrm{AWEI}_{\mathrm{sh}}$, which is primarily designed to remove shadow pixels, and $\mathrm{AWEI}_{\mathrm{nsh}}$, for areas with an urban background. Owing to the dominating spectral characteristics of the green and red bands compared with the NIR and MIR bands, the water ratio index (WRI) shows values greater than 1 for water. ${ }^{(41)}$ To obtain a higher accuracy from these indexes, a threshold appropriate for separating water and background classes should be identified. As the threshold varies with the location and time of image acquisition, it is a challenging and time-consuming task. Most works have focused on the Otsu threshold, ${ }^{(42)}$ which is designed to distinguish between background and foreground in imagery by creating two classes with minimal intraclass variance. Malahlela ${ }^{(29)}$ formulated the simple water index (SWI) method, in which vegetation pixels with negative values are suppressed automatically (nullified), whereas water pixels are enhanced, and differentiation requires no threshold determination or input. A pixel value below 5 represents the actual water pixels, whereas any pixel values greater than or equal to 5 represent waterlike pixels such as built-up areas and shadows. Beside water indices, some other indices can also be used for water feature extraction; an example of such indices is the normalized difference vegetation index (NDVI), ${ }^{(4)}$ which shows a unique negative value. ${ }^{(10)}$

Surface water change detection mapping is usually performed in the following two steps: extracting water features from each multidate satellite image and then comparing individual date water features to detect changes. ${ }^{(10,12,16,44)}$ Hence, the proposed concept is that using the same threshold in the same month, i.e., similar season images, could minimize the threshold problem, and that differencing while performing change detection could lead to accurate change mapping without extra effort on computing and field works. 
The change detection of automated surface water features using water indices can be beneficial to countries like Nepal with insufficient historical data and difficult accessibility. Hence, in this study, we use water indices to delineate water features using the standard and Otsu thresholds in three test sites using Landsat data of significant year gaps. A model is developed in ArcGIS by differencing the water features derived using index methods and the difference is calculated for positive and negative changes. The water indexes used are NDVI, NDWI, MNDWI, WRI, and SWI for surface water extraction and its corresponding changes. The method can be useful for understanding the efficiency of water indices for mapping water features and their changes.

\section{Materials and Methods}

To attain the objectives of the study, the following tasks were performed: selection of test sites, data collection, image preprocessing, surface water extraction using a water index method in each image, and change detection in each test site. All the processes were carried out in ENVI 5.1 and ArcGIS 10.3 and R 3.3.1 software packages. Figure 1 shows the overall method adopted for mapping surface water changes in different test sites of Nepal.

\subsection{Test site}

Nepal is a geographically diverse country with varying physiology. Hence, to represent its water systems and varying physiology, one test site from each of the three physiological regions, i.e., Terai, Hilly, and Himalayan, was selected. Then, three test sites with two lakes and a river were selected for the study in different regions of Nepal. Figure 2 shows the location map of the test sites for this study.

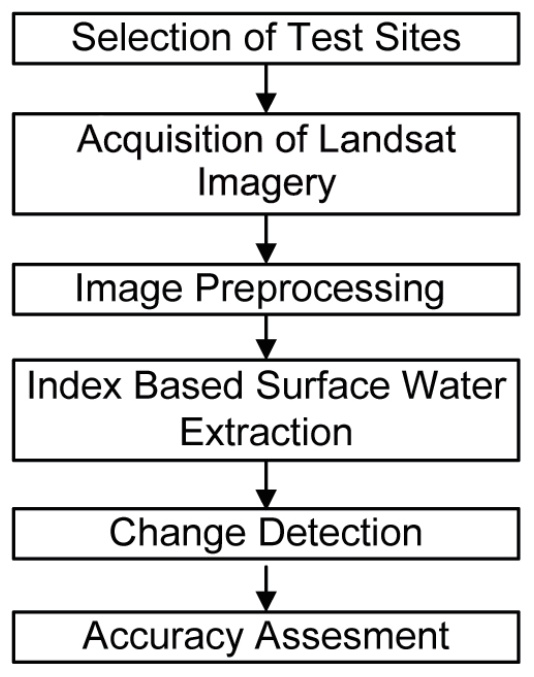

Fig. 1. Overall flowchart adopted in this study. 


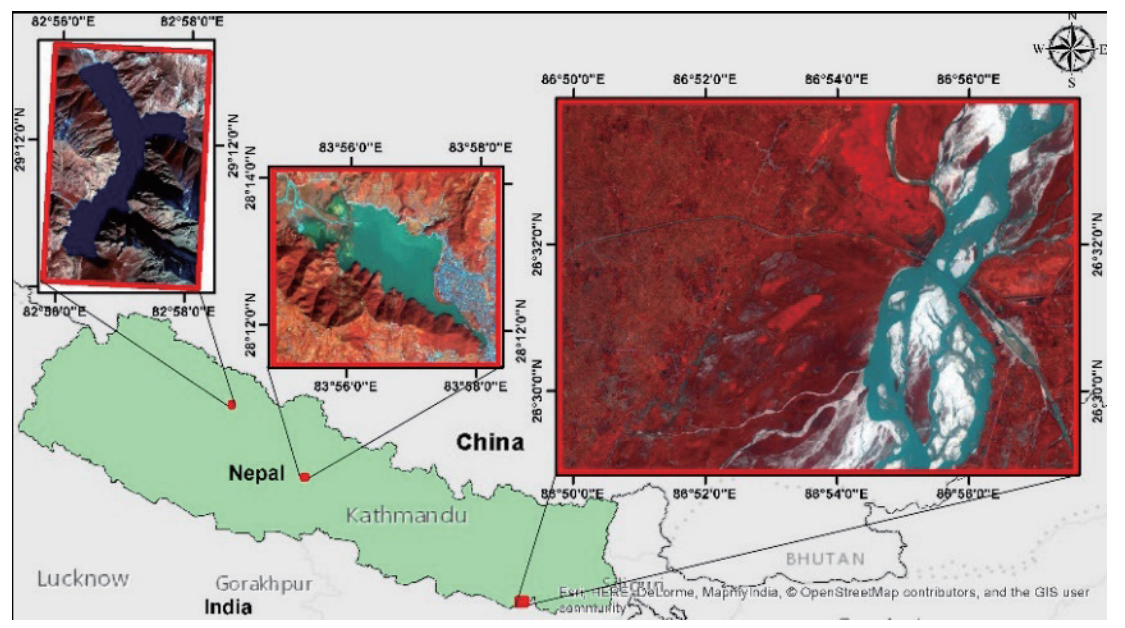

Fig. 2. (Color online) Location map of the test sites in Nepal. False-color composite images (NIR-blue-green) of Landsat 8 taken in different years are shown. Each red box represents the area of the test site.

The first test site is Sheyphoksundo Lake, located at an altitude of $3611.5 \mathrm{~m}$ in Dolpa District. It is an alpine fresh water oligotrophic lake that covers an area of $4.94 \mathrm{~km}^{2}$ with a length of $5.15 \mathrm{~km}$ and a width of $800 \mathrm{~m}$. With a maximum depth of $145 \mathrm{~m}$, it is one of the deepest lakes and represents the water features observed in high Himalayas, which are difficult to use in measuring the surface area for a regular update. Only remote sensors can provide better areal monitoring in this area. The area also has religious importance as it has more than 20 stupas in the southern belt and one gumba on the eastern side, which attracts many Buddhist and Tibetan culture worshipers.

The second test site is Phewa Lake, located at an altitude of $742 \mathrm{~m}$ in the famous tourist city Pokhara. It is the most popular and second largest lake among the seven lakes in Pokhara as a tourist spot and many commercial activities happen around the lakes. It covers an area of approximately $4.43 \mathrm{~km}^{2}$ and has an average depth of $8.6 \mathrm{~m}$ and a maximum depth of $24 \mathrm{~m}$. The source of water in these lakes is mostly monsoon rain and the seepage from the surrounding mountains. The lake gradually fills up and the surface area and volume decrease with urban activities around it. One side of the lake is a steep sloped dense forest and the other side is a dense urban area.

The third test site is Koshi River, which has a flood control sluice across Koshi River (largest in Nepal in terms of discharge) near the border of Nepal and India in Sunsari District and Saptari District. It is a large river that changes its course with each monsoon rain. In 2008, the eastern embankment of the river collapsed and resulted in flood that displaced more than fifty thousand people in Nepal and three million people in Bihar, India. The northwestern part of the study area in Koshi consists of rural villages with many ponds for commercial fishery. The area of these ponds varies according to water storage recharged by rainfall or artificial pumping of underground water. 


\subsection{Data}

For this study, Landsat 7 ETM+ and Landsat 8 OLI images were used. Each test site has one ETM+ image and one OLI image, which are taken in a span of more than a decade. The Level 1 Terrain-Corrected (L1T) data pre-georeferenced using the WGS84 datum were collected from the United States Geological Survey (USGS) Global Visualization Viewer (GLOVIS) portal (http:// glovis.usgs.gov/). The selection of the images was carried out in the same season and dates to remove sun illumination differences and differences in soil and vegetation conditions. Table 1 shows the specifications of the selected Landsat images for the test sites.

\subsection{Image preprocessing}

Each image obtained was preprocessed before deriving the water index. In this process, the image was subjected to radiometric calibration, subsetting, and atmospheric correction. In Environment for Visualizing Images (ENVI) version 5.1, using a radiometric calibration tool, the image was converted from a digital number (DN) to a top-of-atmosphere (TOA) reflectance. The tool uses all the required information of the conversion for the Landsat header MTL metadata file. During the radiometric calibration, both the multispectral and panchromatic images of all test sites were subsetted and extracted for convenient and focused processing as shown in Fig 1. The dark object subtraction (DOS) method was applied to each subsetted multispectral image for any atmospheric corrections.

\subsection{Index-based surface water extraction}

Surface water extraction from each image for two different times is the primary task for change detection. For this purpose, surface water was extracted using various index methods, namely, NDVI, ${ }^{(43)}$ NDWI, ${ }^{(33)}$ MNDWI, ${ }^{(31)}$ WRI, and SWI. ${ }^{(29)}$ The water index and threshold

Table 1

Specifications of the selected Landsat images for test sites.

\begin{tabular}{|c|c|c|c|c|c|}
\hline Satellite sensor & $\begin{array}{l}\text { Wavelength } \\
\qquad(\mu \mathrm{m})\end{array}$ & Test site & Path/Row & $\begin{array}{l}\text { Acquisition } \\
\text { date }\end{array}$ & $\begin{array}{l}\text { Resolution } \\
\text { (m) }\end{array}$ \\
\hline \multirow{5}{*}{ Landsat 7 ETM+ } & $\begin{array}{l}\text { Band 1: } 0.45-0.515 \\
\text { Band 2: } 0.525-0.605\end{array}$ & Sheyphoksundo Lake & $115 / 34$ & 29-Nov-99 & \multirow{13}{*}{30} \\
\hline & Band 3: 0.63-0.69 & & & & \\
\hline & Band 4: $0.75-0.90$ & Phewa Lake & $115 / 34$ & $3-\mathrm{Nov}-02$ & \\
\hline & Band 5: 1.55-1.75 & & & & \\
\hline & Band 7: 2.09-2.35 & Koshi River & $140 / 42$ & 20-Nov-00 & \\
\hline \multirow{8}{*}{ Landsat 8 OLI } & Band 1: $0.435-0.451$ & \multirow{4}{*}{ Sheyphoksundo Lake } & \multirow{4}{*}{$15 / 34$} & \multirow{4}{*}{ 27-Nov-13 } & \\
\hline & Band 2: $0.452-0.512$ & & & & \\
\hline & Band 3: $0.533-0.590$ & & & & \\
\hline & Band 4: $0.636-0.673$ & & & & \\
\hline & Band 5: 0.851-0.879 & Phewa Lake & $115 / 34$ & 1-Nov-16 & \\
\hline & Band 6: 1.566-1.651 & \multirow{3}{*}{ Koshi River } & \multirow{3}{*}{$140 / 42$} & \multirow{3}{*}{ 19-Nov-14 } & \\
\hline & Band 7: 2.107-2.294 & & & & \\
\hline & Band 9: $1.363-1.384$ & & & & \\
\hline
\end{tabular}


for the binary classification of water and nonwater backgrounds were derived according to the remarks shown in Table 2 and the Otsu method.

\subsection{Surface water change detection}

For each test site, the surface water map derived from the ETM+ image was given a negative $(-1)$ value, whereas that from the OLI image was given a positive $(+1)$ value. An additive operation on these two water features will result in unchanged $(0)$, decreased $(-1)$ and increased $(+1)$ class as in a raster layer. The proposed surface water change detection approach shown in Fig. 3 will be applied to each site to produce a change map.

\subsection{Accuracy assessment}

Even though the purpose of the easy application of water index methods here is to produce accurate change maps over time without extra evaluation cost and time, the proposed method should be verified for accuracy. As the images are historic and the water surface changes often, there is no database of water features at that exact point of time. However, in Landsat ETM+ and OLI, there is a $15 \mathrm{~m}$ high-resolution-panchromatic band, which itself acts as the validation data for the exact point of time. Thus, by using a panchromatic image and its derivative, i.e., the true-color pan-sharpened image, reference surface water features were generated very carefully

Table 2

Multiband indexes used for water feature extraction.

\begin{tabular}{lccc}
\hline Multiband index & Equation & Remarks & Reference \\
\hline NDVI & NDVI $=($ NIR - Red $) /($ NIR + Red $)$ & Water with negative value & $(43)$ \\
\hline NDWI & MNDI $=($ Green - NIR $) /($ Green + NIR $)$ & Water with positive value & $(33)$ \\
\hline MNDWI $=($ Green - SWIR1 $) /$ & Water with positive value & $(31)$ \\
\hline WRI & WRI $=($ Green + Red $) /($ NIR + SWIR1 $)$ & $\begin{array}{c}\text { Water feature value } \\
\text { is greater than } 1\end{array}$ \\
\hline SWI & SWI $=1 / \sqrt{(\text { Blue }- \text { SWIR1 })}$ & $\begin{array}{c}\text { Water feature value } \\
\text { is less than } 5\end{array}$ \\
\hline
\end{tabular}

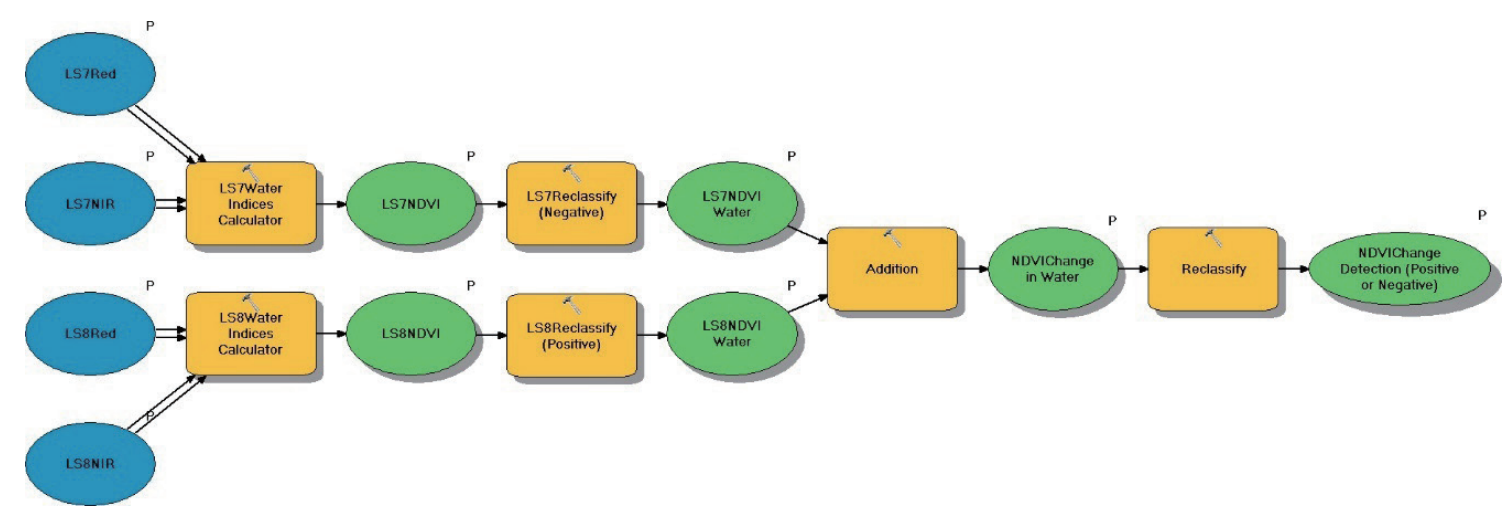

Fig. 3. (Color online) Change detection process from Landsat 7 ETM+ and Landsat 8 OLI in ArcGIS. 
by the on-screen digitization of both Landsat ETM+ and OLI images by the visual interpretation of an expert's knowledge. As per the change detection process, three change classes were derived for each site as reference.

The performance characteristics were compared using the overall accuracy (OA) and kappa coefficient calculated from the confusion matrix developed on the basis of the reference and derived index-based change maps. Table 3 shows the principle of a typical confusion matrix, where $a$ is the number of correct predictions that an instance is negative, $b$ is the number of incorrect predictions that an instance is positive, $c$ is the number of incorrect predictions that an instance is negative, and $d$ is the number of corrections that an instance is positive. ${ }^{(45)}$ The calculations of the OA and kappa coefficient are shown as

$$
\begin{gathered}
\text { Overall accuracy }=\frac{\text { Number of correct predictions }}{\text { Total predictions }}, \\
\text { Kappa coefficient }=\frac{\text { Observed accuracy }- \text { Chance accuracy }}{1-\text { Chance accuracy }} .
\end{gathered}
$$

The OA represents the current predictions and ranges from 0 to 1 , where a value near 1 is perfect. However, it does not consider the agreements between datasets that are due to chance alone. Hence, the kappa coefficient, a tool to control that random agreement factor, is often used together. Usually, the kappa coefficient can range from -1 to +1 , where 0 represents the amount of agreement that can be expected from random chance and 1 represents a perfect agreement between the raters. In very rare cases, the kappa coefficient can be negative, indicating that there is no effective agreement between the two raters. ${ }^{(46)}$

\section{Results and Discussion}

After the radiometric calibration, subsetting, and DOS correction, all the test site images were processed for the derivation of water indices. The water indices were then converted into water and nonwater features using two binary thresholding techniques. The first thresholding was carried out according to the previously used threshold as in the literature (Table 2), whereas the second thresholding was carried out using the Otsu-method-based binary thresholding function of ArcGIS software for the automatic separation of water and nonwater rasters. After separation, each raster was reclassified such that the background was assigned " 0 ", whereas water of Landsat ETM+ (older) was assigned " -1 " and that of Landsat OLI (new) was assigned "+1". Each test site and each index method derived a raster that underwent an additional operation so

Table 3

Principle of the confusion matrix.

\begin{tabular}{lccc}
\hline & \multicolumn{2}{c}{ Predicted } \\
\cline { 3 - 4 } & & Negative & Positive \\
\hline \multirow{2}{*}{ Truth } & Negative & $\mathrm{a}$ & $\mathrm{b}$ \\
& Positive & $\mathrm{c}$ & $\mathrm{d}$ \\
\hline
\end{tabular}


that unchanged regions become " 0 ". The addition results in "- 1 " for older pixels but not for new ones, i.e., a decrease in area. Similarly, pixels that are in new images but not in old ones become "+1", i.e., an increase in area. Thus, the changes in two different dates based on an index method without any intervention were derived.

A tool was developed in ArcGIS using ModelBuilder for the automated output. Figure 3 shows one of the tools developed for the process using NDVI in this study. Blue ovals are input bands, yellow rectangles are tools, and green ovals are outputs. The water index calculator uses a map algebra according to the equation available in Table 2. A reclassify tool labels the pixels. In the reclassification of each Landsat image, each method is repeated for the threshold in Table 2 and the Otsu method. The binary thresholding function in ArcGIS does not provide the threshold value; hence, only the output was applied without them. By using the model, water (blue) and nonwater (grey) maps were prepared, then change maps with decrease (red), unchanged (grey), and increase (green) in water features in the area were derived. The results of the tool are shown in Fig. 4, A1, A2, A3, and 5.

NDVI is an index of plant greenness that is due to red light absorption and NIR reflection by plants. Its value ranges from -1 to +1 . However, water does quite the opposite, which absorbs most of the NIR light; hence, NDVI could be used as the tool to delineate surface water features, i.e., negative value range. Figure 5 shows the result of surface water feature extraction and its application in change detection. Except Phewa Lake, the other two have very little vegetative features around them, which has led to very poor segregation based on the threshold of less than 0 . In the case of Sheyphoksundo Lake, the shadow due to high Himalayas on the southeast corner has been a large issue, which has also not been resolved by the Otsu method thresholding. In the case of Phewa Lake that is being surrounded by a forest farm land and a city area, NDVI did well in segregating water and nonwater features. However, owing to the limitation of the Landsat ETM+ radiometric resolution, the slight greenness from the algae of the lake led to few nonwater pixels inside the lake. The problem was solved well by the Otsu method, but it led to the misclassification of the wider black topped road as a water feature within the processed scene. The change map shows few pixels encroached in the southwest city area owing to hotel and leisure businesses. Moreover, the growth in the northwestern side is probably due mostly to the recent rainfall that increased the flow of water to the lake. In fact, the gradual growth of the lake area is also negative on that side. The study area around Koshi River is mostly barren sand, grass, and shrub with few cultivable and forest lands. Hence, NDVI did very well in delineating the water features of the study area and in clarifying the changes. It identified the water stored around the barrage as unchanged but failed to identify the water-filled canal in the recent Landsat 8 image. The issue has been resolved by the Otsu method. However, due to less variance in the area, the method misclassified wet/dry sand in the floodplain as a water feature.

NDWI is an analogy of NDVI but for water. A higher NDWI denotes water and lower nonwater features. MNDWI was developed to overcome the limitations of NDWI. Including WRI, these indices utilize the unique spectral properties of green, red, NIR, and MIR bands. The results of the methods based on these indices are shown in Appendix A. In most cases, the results resemble each other, where WRI seems to be much superior with standard and Otsu thresholds compared with NDWI and MNDWI. Both NDWI and MNDWI were less effective 


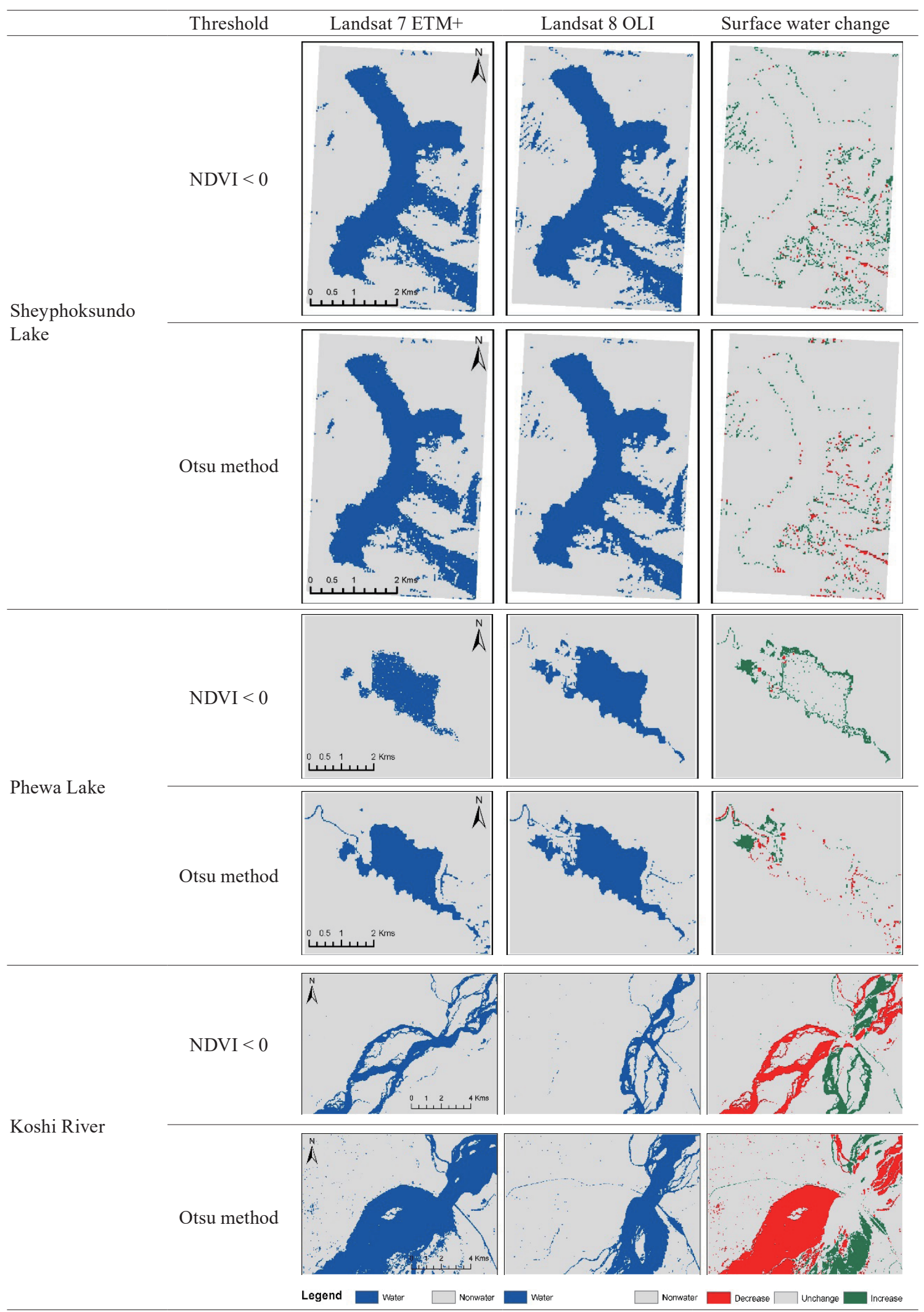

Fig. 4. (Color online) Results of surface water identification and change detection using NDVI at three test sites. 


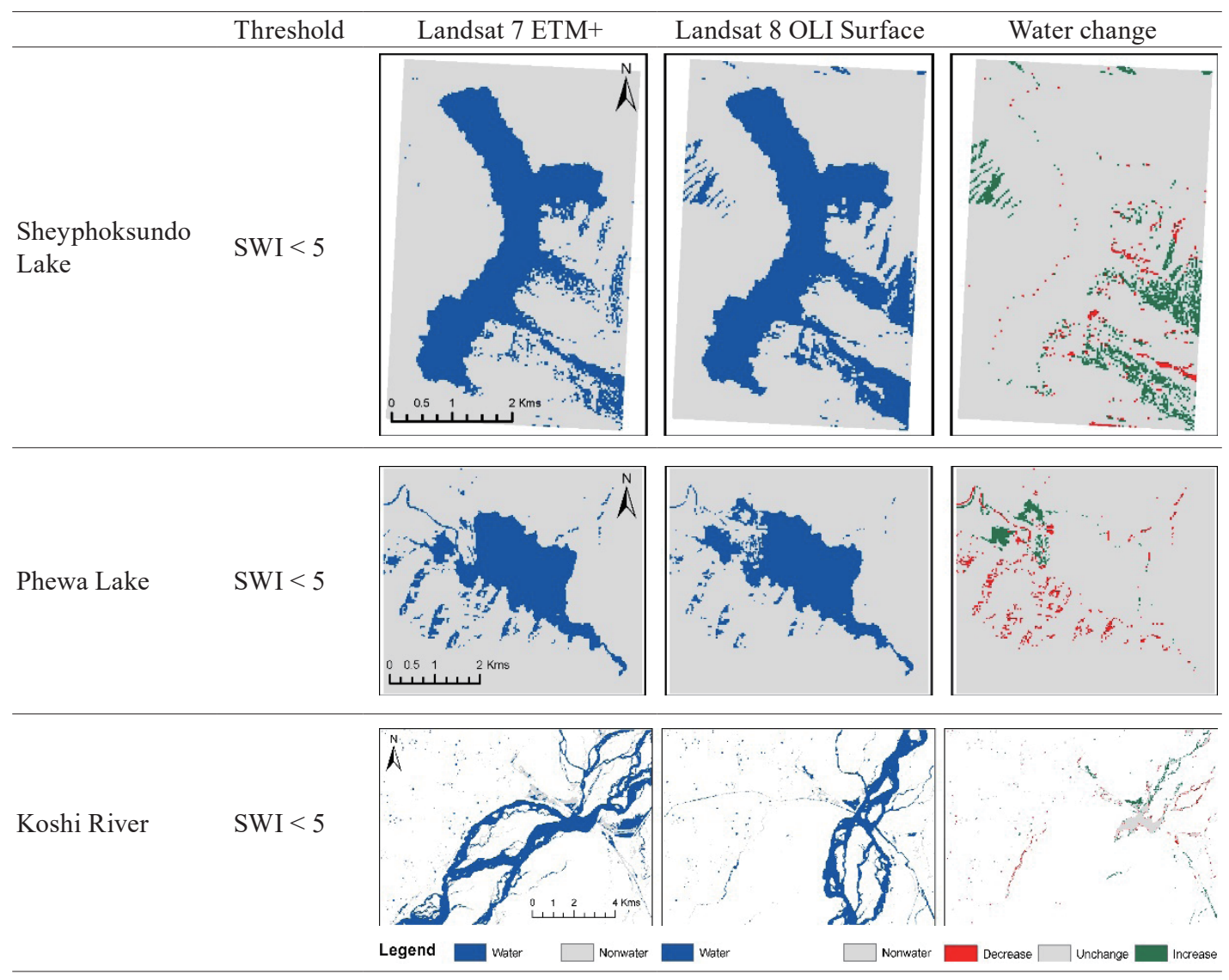

Fig. 5. (Color online) Results of surface water identification and change detection using SWI at three test sites.

in the shadow region of the Himalayas in Sheyphoksundo and Phewa Lakes. WRI was less effective in Phewa Lake forest shadows than in Himalayan shadows in Sheyphoksundo Lake. The Otsu method almost removed the shadows in the WRI case for Landsat 8 scenes in both cases but was unable in the Landsat 7 scene of Sheyphoksundo Lake. However, in the case of the shadow-free but barren floodplain of Koshi River, the results were good for the large water channel in the river, but many cases failed to determine the canal line and some could do it partially. The limitation in the partial pixel identification of a canal is logical as the width of the canal is smaller than the spatial resolution of imagery and is affected by the deposited silts, grown vegetation, and outgoing water from the channel through spill or seepage. The fishery ponds in the northwestern regions were also well identified in most of the cases. The change in the flow path of the river can be distinctly visible in all the cases of NDWI, MNDWI, and WRI. Visually, most of the cases have noise based on the standard threshold; only the Otsu thresholding was able to provide clear water bodies in a few cases.

SWI is a recently developed water index for Landsat OLI to solve the thresholding problem for water and backgrounds resembling water. Hence, the Otsu threshold was not used in this case. The uniqueness of this index is that it nullifies vegetative features so that only water and waterlike features are assigned pixel values whereas others are marked "No data". The standard that SWI $<5$ representing water also fails mostly in dark Himalayan and forest shadows. 
However, in the case of Koshi River, it identified water as well as a few wetlands near the river channel, which are not detected in another case.

For the accuracy assessment of each method, a reference map for each Landsat in each site was prepared and the change was detected using the developed tool. Figure 6 shows the water features and changes identified for the validation. In the case of Sheyphoksundo Lake, the decrease in water level resulted in a decrease in area on all sides whereas the southwest part showed a small increase due to erosion and an increase in area. Phewa Lake water during Landsat 7 had a continuous water flow in the upper input of the lake, while it was not observed in the case of Landsat 8, which could be the result of recent rainfall. Koshi River showed a marked change in its course, which shifted from west to east. Similarly, the canals in eastern parts were broken owing to the deposited silt, narrow deep channels, which are not detectable with the resolution of the Landsat. On the basis of the reference map, the OA and kappa coefficient were calculated and are tabulated in Tables 4 and 5, respectively.

On average, the OAs of the case studies for water detection, as well as the kappa coefficient, are high. In contrast, the OAs of the changes are high, but the kappa coefficients are low except in a few cases. The OA of Sheyphoksundo Lake is lower than 0.90, compared with those of other sites, especially in water feature mapping. However, the average accuracy in the change detection of water features in the site is 0.981 , which is good statistically, but the

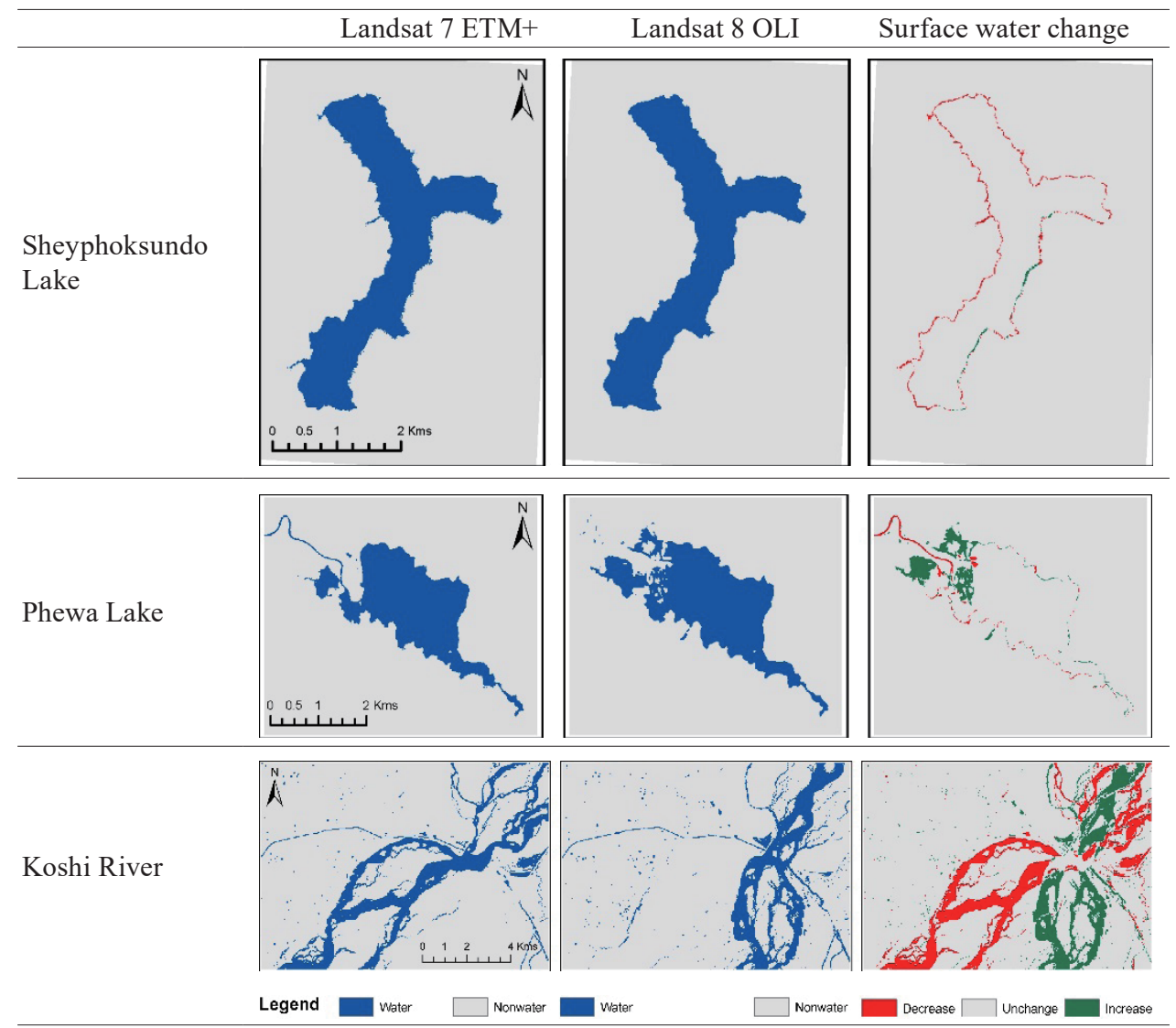

Fig. 6. (Color online) Results of surface water identification and change detection for validation at three test sites. 
kappa coefficient tells otherwise. The negative value clarifies that it does not agree with the higher accuracy. This is due to less changes in the two dates and clustered water and nonwater features, i.e., the lake surrounded by mountains. The Otsu method in a Koshi River site has the lowest $\mathrm{OA}$ in water feature extraction and thus affects the accuracy of change detection. As the Otsu method attempts to minimize the intraclass variance, the number of pixels and the index play very important roles. The wet sandy area of the floodplain has no vegetation, which is assigned a null NDVI value, thus making it much closer to the river than to the remaining farmland and forests. Similarly, in the same Koshi River site, SWI showed the lowest accuracy owing to the "No data" assignment to nonwater features. In many cases, the Otsu method improves the segregation of water features compared with the standard thresholding based on water indices. The dependence of the atmospheric and environmental conditions in the study alters the threshold in each case.

In the literature, most of the studies conducted are ideal and real difficult regions are avoided. In previous studies conducted by many researchers, the water bodies considered are natural large lakes and reservoirs such as dams and have a surrounding distinguishing but homogenous background..$^{(10,13,23)}$ Thus, this results in a very high accuracy statistically

Table 4

OAs of all water and change maps in all three sites.

\begin{tabular}{|c|c|c|c|c|c|}
\hline Test site & Water index & Threshold & $\begin{array}{c}\text { Landsat } 7 \\
\text { ETM+ }\end{array}$ & $\begin{array}{c}\text { Landsat } 8 \\
\text { OLI }\end{array}$ & $\begin{array}{c}\text { Surface water } \\
\text { change }\end{array}$ \\
\hline \multirow{9}{*}{ Sheyphoksundo Lake } & \multirow{2}{*}{ NDVI } & NDVI $<0$ & 0.881 & 0.868 & 0.983 \\
\hline & & Otsu method & 0.882 & 0.887 & 0.987 \\
\hline & \multirow{2}{*}{ NDWI } & NDWI $>0$ & 0.869 & 0.843 & 0.987 \\
\hline & & Otsu method & 0.845 & 0.875 & 0.988 \\
\hline & \multirow{2}{*}{ MNDWI } & MNDWI > 0 & 0.840 & 0.840 & 0.981 \\
\hline & & Otsu method & 0.867 & 0.872 & 0.982 \\
\hline & \multirow{2}{*}{ WRI } & WRI $>1$ & 0.858 & 0.853 & 0.983 \\
\hline & & Otsu method & 0.968 & 0.982 & 0.986 \\
\hline & SWI & $\mathrm{SWI}<5$ & 0.930 & 0.881 & 0.955 \\
\hline \multirow{9}{*}{ Phewa Lake } & \multirow{2}{*}{ NDVI } & NDVI $<0$ & 0.952 & 0.967 & 0.961 \\
\hline & & Otsu method & 0.984 & 0.973 & 0.978 \\
\hline & \multirow{2}{*}{ NDWI } & NDWI $>0$ & 0.982 & 0.976 & 0.980 \\
\hline & & Otsu method & 0.988 & 0.976 & 0.980 \\
\hline & \multirow{2}{*}{ MNDWI } & MNDWI $>0$ & 0.946 & 0.973 & 0.969 \\
\hline & & Otsu method & 0.967 & 0.967 & 0.968 \\
\hline & \multirow{2}{*}{ WRI } & WRI > 1 & 0.987 & 0.980 & 0.982 \\
\hline & & Otsu method & 0.981 & 0.958 & 0.972 \\
\hline & SWI & SWI $<5$ & 0.966 & 0.978 & 0.967 \\
\hline \multirow{9}{*}{ Koshi River } & \multirow{2}{*}{ NDVI } & NDVI $<0$ & 0.962 & 0.953 & 0.933 \\
\hline & & Otsu method & 0.747 & 0.892 & 0.741 \\
\hline & \multirow{2}{*}{ NDWI } & NDWI $>0$ & 0.955 & 0.957 & 0.927 \\
\hline & & Otsu method & 0.964 & 0.957 & 0.937 \\
\hline & \multirow{2}{*}{ MNDWI } & MNDWI $>0$ & 0.967 & 0.960 & 0.940 \\
\hline & & Otsu method & 0.957 & 0.952 & 0.927 \\
\hline & \multirow{2}{*}{ WRI } & WRI > 1 & 0.968 & 0.957 & 0.940 \\
\hline & & Otsu method & 0.940 & 0.940 & 0.904 \\
\hline & SWI & SWI $<5$ & 0.971 & 0.962 & 0.796 \\
\hline
\end{tabular}


Table 5

Kappa coefficients for all water and change maps in all three sites.

\begin{tabular}{|c|c|c|c|c|c|}
\hline Test site & Water index & Threshold & $\begin{array}{c}\text { Landsat } 7 \\
\text { ETM+ }\end{array}$ & $\begin{array}{c}\text { Landsat } 8 \\
\text { OLI }\end{array}$ & $\begin{array}{c}\text { Surface water } \\
\text { change }\end{array}$ \\
\hline \multirow{9}{*}{$\begin{array}{l}\text { Sheyphoksundo } \\
\text { Lake }\end{array}$} & \multirow{2}{*}{ NDVI } & NDVI $<0$ & 0.679 & 0.657 & -0.005 \\
\hline & & Otsu method & 0.681 & 0.694 & -0.003 \\
\hline & \multirow{2}{*}{ NDWI } & NDWI $>0$ & 0.614 & 0.610 & -0.001 \\
\hline & & Otsu method & 0.659 & 0.672 & -0.003 \\
\hline & \multirow{2}{*}{ MNDWI } & MNDWI $>0$ & 0.605 & 0.603 & -0.007 \\
\hline & & Otsu method & 0.654 & 0.664 & -0.002 \\
\hline & \multirow{2}{*}{ WRI } & WRI > 1 & 0.638 & 0.628 & -0.005 \\
\hline & & Otsu method & 0.897 & 0.942 & -0.006 \\
\hline & SWI & SWI $<5$ & 0.799 & 0.685 & -0.010 \\
\hline \multirow{9}{*}{ Phewa Lake } & \multirow{2}{*}{ NDVI } & NDVI $<0$ & 0.791 & 0.874 & 0.257 \\
\hline & & Otsu method & 0.936 & 0.900 & 0.489 \\
\hline & \multirow{2}{*}{ NDWI } & NDWI $>0$ & 0.928 & 0.914 & 0.506 \\
\hline & & Otsu method & 0.952 & 0.912 & 0.506 \\
\hline & \multirow{2}{*}{ MNDWI } & MNDWI $>0$ & 0.816 & 0.910 & 0.450 \\
\hline & & Otsu method & 0.875 & 0.882 & 0.290 \\
\hline & \multirow{2}{*}{ WRI } & WRI $>1$ & 0.948 & 0.929 & 0.572 \\
\hline & & Otsu method & 0.923 & 0.836 & 0.219 \\
\hline & SWI & $\mathrm{SWI}<5$ & 0.877 & 0.922 & 0.272 \\
\hline \multirow{9}{*}{ Koshi River } & \multirow{2}{*}{ NDVI } & NDVI $<0$ & 0.837 & 0.737 & 0.791 \\
\hline & & Otsu method & 0.372 & 0.594 & 0.368 \\
\hline & \multirow{2}{*}{ NDWI } & NDWI $>0$ & 0.820 & 0.765 & 0.782 \\
\hline & & Otsu method & 0.847 & 0.767 & 0.808 \\
\hline & \multirow{2}{*}{ MNDWI } & MNDWI $>0$ & 0.864 & 0.791 & 0.818 \\
\hline & & Otsu method & 0.803 & 0.732 & 0.765 \\
\hline & \multirow{2}{*}{ WRI } & WRI > 1 & 0.864 & 0.765 & 0.815 \\
\hline & & Otsu method & 0.706 & 0.646 & 0.674 \\
\hline & SWI & SWI $<5$ & 0.874 & 0.801 & 0.042 \\
\hline
\end{tabular}

as well as aesthetically. However, it is usually not the case as the condition varies. Hence, semi-automated methodologies can be used for faster outputs in change detection, but human intervention during and after processing can never be avoided.

\section{Conclusions}

In this study, we applied and explored the effectiveness of five well-known water indices to extract surface water features and detect changes in using two Landsat 7 and 8 images taken in a decade for three different test sites. Each site represented unique but common water bodes in Nepal. On the basis of visual interpretation and statistics, most index methods identified water features as well as shadow features. Compared with the standard threshold, the Otsu method provided better segregation of water depending on the water and surrounding features. However, it is not recommended to use standard water indices for mapping purposes in Nepal. Except for Sheyphoksundo Lake where the change was not significant, surface water changes in most cases were well identified with higher accuracy. SWI is good for nonshifting water features, such as in lakes and reservoirs, but not for shifting features, such as in Koshi River. 
The method can also be used in change detection of any feature in features if indexes and threshold are chosen carefully to separate the object of interest from its background. Future works require the appropriate calibration of the threshold for the identification of water bodies for different seasons, sensor data, and sites using standard water indices for accurate change detection.

\section{Acknowledgments}

This work was supported by the National Research Foundation of Korea (NRF) grant funded by the Korea government (MSIT) (No. 2018R1A2B6009363). We are grateful to the U.S. Geological Survey (http://glovis.usgs.gov) for freely providing the Landsat data used in this manuscript. We would also like to thank the anonymous reviewers for their constructive comments and English editor from MYU Research.

\section{References}

1 J. Hoffmann and P. Sander: Hydrogeol. J. 15 (2007) 1.

2 N. R. Khanal, S. R. Chalise, and A. P. Pokhrel: Proc. Int. Conf. Ecohydrology of High Mountain Areas (1996) 49.

3 WECS: Water Resources of Nepal in the Context of Climate Change (2011). http://www.wecs.gov.np/uploaded/ water-recource-climate-change.pdf

4 U. R. Bhuju, M. Khadka, P. K. Neupane, and R. Adhikari: National Lakes Conservation Development Committee Report SP01 (2009). https://ntnc.org.np/sites/default/files/doc_publication/2018-11/lake1.pdf

5 S. Pokharel and M. Nakamura: Wetland Conservation Publication Series 2 (2010) 15

6 T. D. Acharya, A. Subedi, and D. H. Lee: Sensors 8 (2018) 2580.

7 T. D. Acharya, A. Subedi, I. T. Yang, and D. H. Lee: Proc. 2 (2018) 143.

8 T. D. Acharya, I. T. Yang, A. Subedi, and D. H. Lee: Proc. 1 (2017) 17.

9 T. D. Acharya, I. T. Yang, K. W. Yoo, and D. H. Lee: 2016 Con. Korean Society for Geospatial Information Science (2016) 135.

10 K. Rokni, A. Ahmad, A. Selamat, and S. Hazini: Remote Sens. 6 (2014) 4173.

11 H. Jiang, M. Feng, Y. Zhu, N. Lu, J. Huang, and T. Xiao: Remote Sens. 6 (2014) 5067.

12 X. Wang, Y. Liu, F. Ling, Y. Liu, and F. Fang: ISPRS Int. J. Geo-Inf. 6 (2017) 68.

13 T. D. Acharya, D. H. Lee, I. T. Yang, and J. K. Lee: Sensors 16 (2016) 1075.

14 Y. Yang, Y. Liu, M. Zhou, S. Zhang, W. Zhan, C. Sun, and Y. Duan: Remote Sens. Environ. 171 (2015) 14.

15 L. Li, H. Xia, Z. Li, and Z. Zhang: Remote Sens. 7 (2015) 10364.

16 Z. Du, B. Linghu, F. Ling, W. Li, W. Tian, H. Wang, Y. Gui, B. Sun, and X. Zhang: J. Appl. Remote Sens. 6 (2012) 063609.

17 Y. Wang, R. Ruan, Y. She, and M. Yan: Proc. Environ. Sci. 10 (2011) 2301.

18 M. Ma, X. Wang, F. Veroustraete, and L. Dong: Int. J. Remote Sens. 28 (2007) 5523.

19 W. Li and Q. Zhang: Proc. SPIE 6419 (2006) 641911.

20 P. S. Frazier and K. J. Page: Photogramm. Eng. Remote Sens. 66 (2000) 1461.

21 P. Li, L. Jiang, and Z. Feng: Remote Sens. 6 (2013) 310.

22 A. Fisher, N. Flood, and T. Danaher: Remote Sens. Environ. 175 (2016) 167.

23 B. C. Ko, H. H. Kim, and J. Y. Nam: Sensors 15 (2015) 13763.

24 G. L. Feyisa, H. Meilby, R. Fensholt, and S. R. Proud: Remote Sens. Environ. 140 (2014) 23.

25 A. Liao, L. Chen, J. Chen, C. He, X. Cao, J. Chen, S. Peng, F. Sun, and P. Gong: Sci. China Earth Sci. 57 (2014) 2305.

26 A. Fisher and T. Danaher: Remote Sens. 5 (2013) 5907.

27 I. Klein, A. J. Dietz, U. Gessner, A. Galayeva, A. Myrzakhmetov, and C. Kuenzer: Int. J. App. Earth Obs. Geoinf. 26 (2014) 335.

28 E. A. Work Jr and D. S. Gilmer: Photogramm. Eng. Remote Sens. 42 (1976) 685.

29 O. E. Malahlela: Int. J. Remote Sens. 37 (2016) 4574.

30 L. Ji, L. Zhang, and B. Wylie: Photogramm. Eng. Remote Sens. 75 (2009) 1307. 
31 H. Xu: Int. J. Remote Sens. 27 (2006) 3025.

32 A. S. Rogers and M. S. Kearney: Int. J. Remote Sens. 25 (2004) 2317.

33 S. K. McFeeters: Int. J. Remote Sens. 17 (1996) 1425.

34 R. Sivanpillai and S. N. Miller: Ecol. Inf. 5 (2010) 73.

35 M. G. Tulbure, M. Broich, S. V. Stehman, and A. Kommareddy: Remote Sens. Environ. 178 (2016) 142.

36 F. Sun, Y. Zhao, P. Gong, R. Ma, and Y. Dai: Chinese Sci, Bull. 59 (2014) 171.

37 M. G. Tulbure and M. Broich: ISPRS J. Photogramm. Remote Sens. 79 (2013) 44.

38 D. K. McIver and M. A. Friedl: Remote Sens. Environ. 81 (2002) 253.

39 J. Ryu, J. Won, and K. D. Min: Remote Sens. Environ. 83 (2002) 442.

40 W. Li, Z. Du, F. Ling, D. Zhou, H. Wang, Y. Gui, B. Sun, and X. Zhang: Remote Sens. 5 (2013) 5530.

41 L. Shen and C. Li: Proc. 18th Int. Conf. Geoinf. (2010) 1.

42 N. Otsu: IEEE Trans. Syst. Man Cybern. 9 (1979) 62.

43 J. W. Rouse, R. H. Haas, J. A. Schell, and D. W. Deering: 3rd Earth Resources Technology Satellite-1 Symposium, NASA SP-351 (1973) 309.

44 H. Jin, C. Huang, M. W. Lang, I. Yeo, and S. V. Stehman: Remote Sens. Environ. 190 (2017) 26.

45 R. G. Congalton and K. Green: Assessing the Accuracy of Remotely Sensed Data: Principles and Practices (CRC Press, Boca Raton, 2008) Chap. 7.

46 M. L. McHugh: Biochemia Medica 22 (2012) 276.

\section{About the Authors}

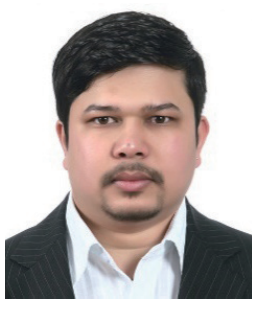

Tri Dev Acharya received his B.E. in Geomatics from Kathmandu University, Nepal, in 2011, and his Combined M.S. and Ph.D. degree from Kangwon National University, Korea, in 2018. He is now a postdoctoral researcher at Kangwon National University, Korea. His research interests include geospatial data preparation, modelling and simulation of land cover, surface water, and natural hazards using various machine-learning algorithms. (tridevacharya@kangwon.ac.kr)

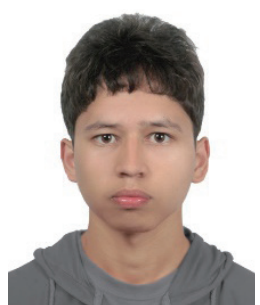

Anoj Subedi is currently pursuing his B.Sc. in Forestry from the Institute of Forestry, Pokhara affiliated to Tribhuvan University, Nepal. He has been involved in various national and international projects and has well contributed in various wildlife and forest surveys. His research interests are related to forest, wildlife, water bodies, land use/cover, and climate change. (anojsubedi99@gmail.com)

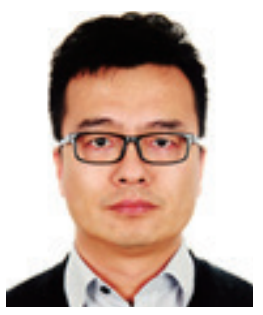

He Huang received his B.Sc. from Wuhan University in 2000 and his M.Sc. and Ph.D. degrees in Geodetic Surveying from Sungkyunkwan University. Currently, he is an associate professor in the School of Geomatics and Urban Spatial Information at Beijing University of Civil Engineering and Architecture. His research interests include GNSS technology and applications, indoor navigation, and positioning. (huanghe@bucea.edu.cn)

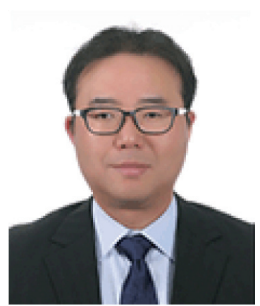

Dong Ha Lee received his B.E., M.S., and Ph.D. degrees from Sungkyunkwan University, Korea, in 2000, 2003, and 2008, respectively. Since 2015, he has been an assistant professor at Kangwon National University, Korea. His research interests are in geodesy, surveying, geospatial information, and natural hazard analysis. (geodesy@kangwon.ac.kr) 


\section{Appendix}

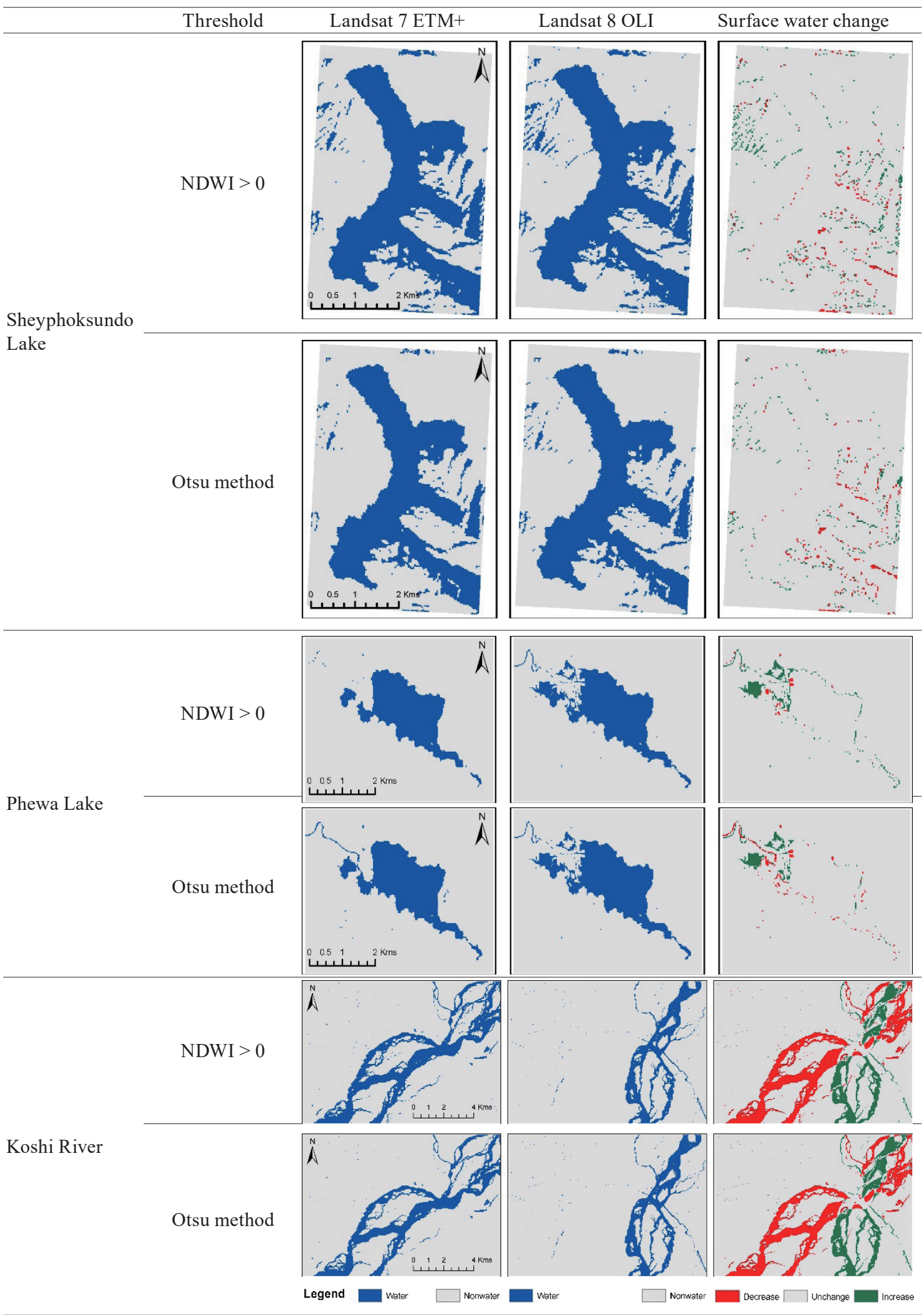

Fig. A1. (Color online) Results of surface water identification and change detection using NDWI at three test sites. 


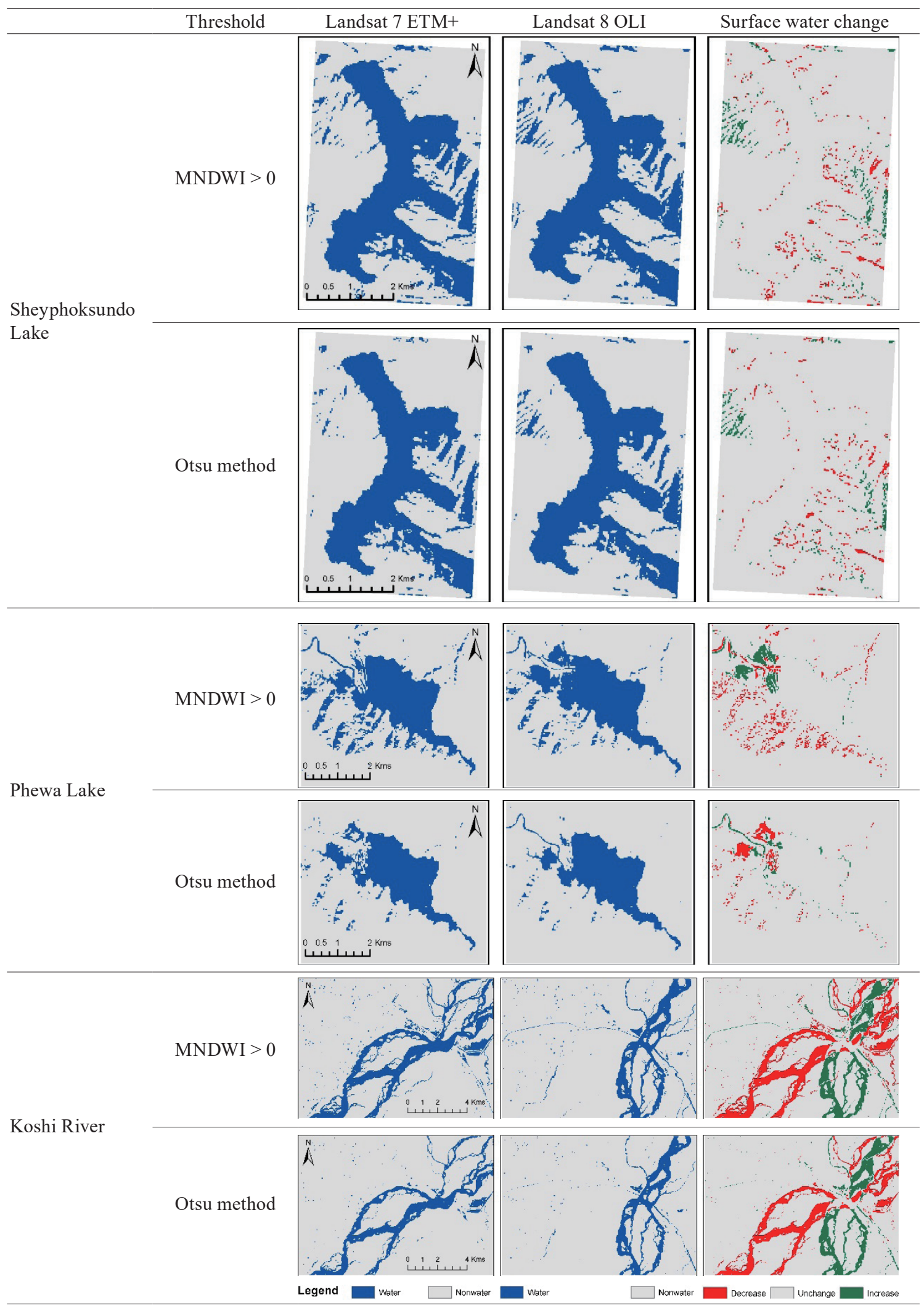

Fig. A2. (Color online) Results of surface water identification and change detection using MNDWI at three test sites. 


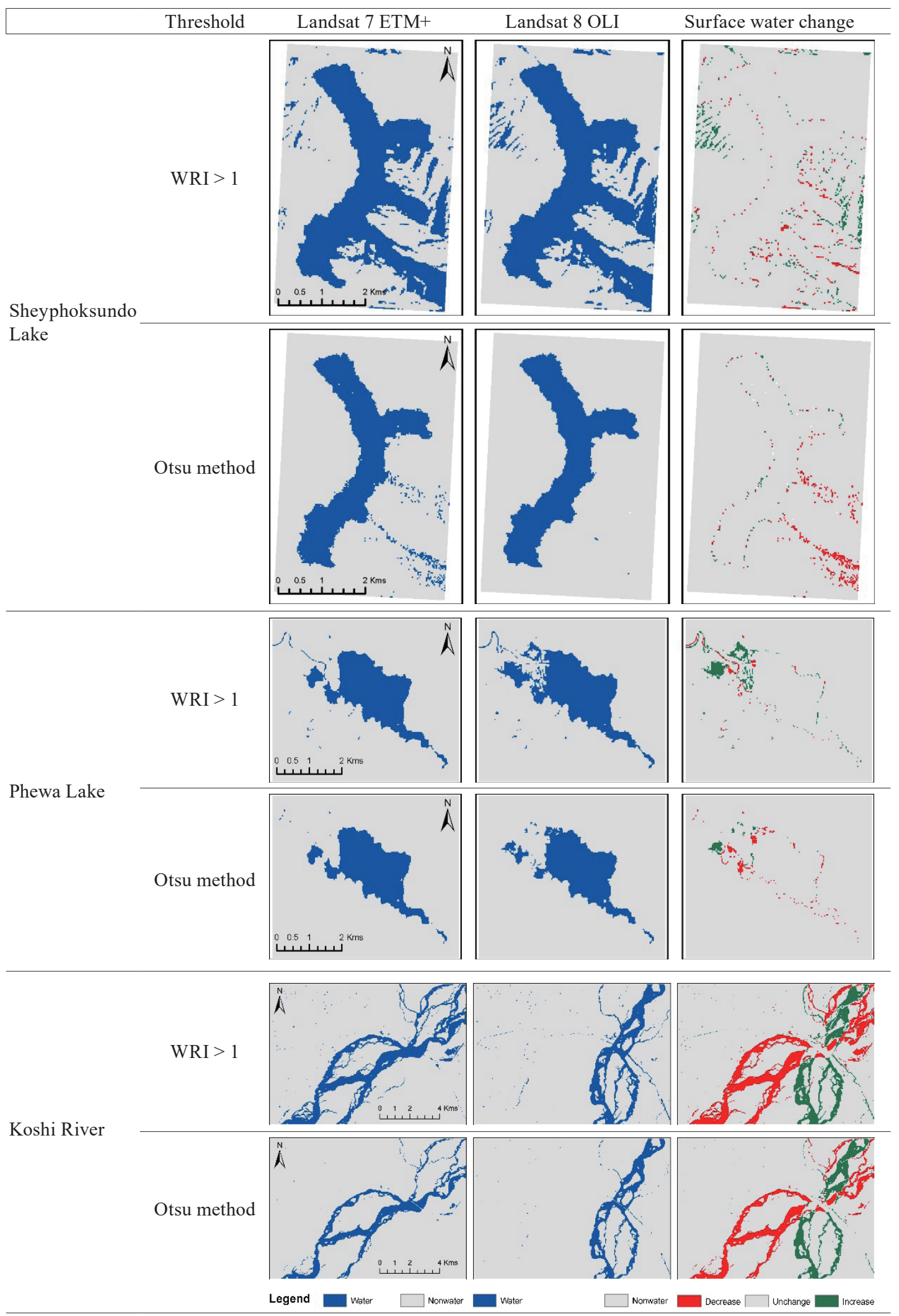

Fig. A3. (Color online) Results of surface water identification and change detection using WRI at three test sites. 